We report our findings in terms of attributable risk rather than coefficients because the attributable risk calculation measures not just the magnitude of the association with the outcome, but also the overall effect of an exposure in a population. ${ }^{1}$ For example, the attributable risk for friend smoking was only $5 \cdot 3 \%$ in a fully adjusted model, and $23.5 \%$ when modeled alone. The difference in effect is due in part because movie-smoking exposure had a stronger effect on the relative risk for smoking initiation than friend smoking, but also because watching smoking in movies was much more common than having friends who smoke. We believe that extrapolation of our findings from a sample of adolescents in northern New England to all adolescents in the USA should be viewed with caution until our results are verified in a nationally representative sample.

Colvin and colleagues suggest that peer influences are the primary cause of adolescent smoking initiation, and that we did not capture this component adequately by including only friend smoking. This notion is a specific example of the general argument that we did not include an important covariate related to both movie-smoking exposure and smoking initiation. We believe the sensitivity analysis, described in our article, adequately addresses this generic criticism. To change the statistical association between movie-smoking exposure and smoking initiation, the missing variable would need to be associated with both movie-smoking exposure and smoking initiation, with $\mathrm{p}$-values orders of magnitude smaller than those we observed, and be independent of all other covariates. Because part of the missing variable is already captured in correlated variables that are included in the model, identifying such a variable is highly unlikely.

Peer pressure could influence movie choices, but because friends tend to watch movies together, it is equally plausible that movie exposure influences peer behaviour. Many stereotypes and images associated with smoking come from movies and other media. By modelling smoking behaviour and influencing norms, movies could promote smoking among peer groups, not just individuals. Previous studies that did not take movie exposure into account might have overestimated the effect of peer behaviour. Further study is needed to fully understand how movie exposure and peer relationships interact to affect smoking in adolescents.
Michael L Beach, *Madeline A Dalton, Todd F Heatherton, James D Sargent Department of Pediatrics, Dartmouth Medical School, Lebanon, NH 03756, USA (e-mail: madeline.a.dalton@dartmouth.edu)

1 Hennekens CH, Buring JE, Mayrent SL, eds. Epidemiology in medicine. Boston: Little, Brown and Company, 1987.

\section{Diabetic environment in utero and predisposition to type 2 diabetes}

Sir-In their Mechanisms of disease article, Eugène Sobngwi and colleagues (May 31, p 1861) ${ }^{1}$ propose that the environment in utero predisposes to type 2 diabetes and to defective insulin secretory responses in offspring of diabetic mothers. We wonder whether genetic imprinting plays a part in the disease process.

Although offspring obtain two complete sets of autosomal chromosomes from both parents, parts of the genes obtained either from the mother or from the father cannot be expressed, a phenomenon called parental imprinting. A potentially important example with respect to diabetes pertains to the IGF2-H19 gene pair, located on chromosome 11 p15.5 near the insulin gene; $;^{2} I G F 2$ is expressed almost entirely on the paternal chromosome, and H19 on the maternal one. This genomic region is of interest to those studying the genetics of type 1 and type 2 diabetes, since the nearby variable number tandem repeat (VNTR) of the insulin gene has a class 1 allele, which predisposes for type 1 diabetes, whereas the class 3 allele, if derived from the father, predisposes for type 2 diabetes, possibly again due to maternal imprinting. ${ }^{3}$ The insulin growth factor 2 (IGF2) receptor is also imprinted, and expression of the maternal gene is essential for the development of functional tissues, including pancreatic $\beta$ cells, during late embryonic development, and for growth regulation. ${ }^{4}$ IGF2 is involved in growth of many tissues, including $\beta$ cells. Indeed, in a preliminary study (unpublished), we observed a correlation between insulin secretion as assessed by glucose clamping and plasma IGF2 concentrations in people.

*T W van Haeften, T B Twickler Department of Internal Medicine, University Medical Center Utrecht (UMCU), G 02.228,

P O Box 85500, NL 3508 GA, Utrecht,

$P$ O Box 855
Netherlands

(e-mail: T.W.vanHaeften@azu.nl)
1 Sobngwi E, Boudou P, Mauvais-Jarvis F, et al. Effect of a diabetic environment in utero on predisposition to type 2 diabetes. Lancet 2003; 361: 1861-65.

2 Srivastava M, Frolova E, Rottinghaus B, et al. Imprint control element-mediated secondary methylation imprints at the Igf2/H19 locus. F Biol Chem 2003; 278: 5977-83.

3 Huxtable SJ, Saker PJ, Haddad L, et al. Analysis of parent-offspring trios provides evidence for linkage and association between the insulin gene and type 2 diabetes mediated exclusively through paternally transmitted class III variable number tandem repeat alleles. Diabetes 2000; 49: 126-30.

4 Wang ZQ, Fung MR, Barlow DP, Wagner EF. Regulation of embryonic growth and lysosomal targeting by imprinted Igf $2 / \mathrm{Mpr}$ gene. Nature 1994; 372: 464-67.

\section{Genetically modified crops in developing countries}

Sir-I disagree with Haroon Ashraf's News item (June 14, p 2051) ${ }^{1}$ about whether genetically modified (GM) crops could help small-scale farmers in developing countries. During a long career in Africa, I noted the use of hybrid crops and the way that small-scale farmers often try to save seeds from these crops for economic reasons. In many cases, I saw poor or failed yield from these second-generation plants (mainly maize).

I am also concerned by three other issues relating to GM crops. First, the well known fear of loss of biodiversity as these plants cross-pollinate with local varieties. Second, the long-term effects of mining the earth to get increased production with better nutritional value - either the land will need regular fertilisers, which is expensive, or it will become depleted. Third, I am concerned by the possibility of transfer of genes. These genes are, as I understand it, transferred from one species through a bacterium, or even virus, to a different species. I do not see what will stop these genes reattaching to suitable bacteria for transfer into a further host. We have already seen the transfer of genes to weeds. Many of these effects may only become obvious after decades, so the science needs to be very precise.

Theresa Watts

41 Orchard Close, Gilwern, Monmouthshire NP7 OEN, UK

(e-mail: tw@twwales.freeserve.co.uk)

1 Ashraf $\mathrm{H}$. UK ethicists say GM foods could help poor. Lancet 2003; 361: 2051 